were generalized tonic clonic, the EEG showed bilateral synchronous epileptiform activity, pulmonary edema was found at autopsy, and a terminal seizure was suspected but not witnessed. Low post-mortem levels of LTG indicated probable non-compliance in 2 patients. Four possible explanations for the SUDEP are proposed: 1) a fatal seizure resulting from LTG non-compliance; 2) LTG-induced ventricular cardiac tachyarrhythmia (torsade de pointes); 3) a combination of LTG effects and seizure; and 4) coincidental unrelated to LTG. (Aurlien D, Tauboll F, Gjerstad L. Lamotrigine in idiopathic epilepsy increased risk of cardiac death? Acta Neurol Scand March 2007;115:199-203). (Respond: Dr Dag Aurlien, Department of Neurology, Stavanger University Hospital, PO Box 8100, 4068 Stavanger, Norway).

COMMENT. LTG is a potential inhibitor of cardiac rapid delayed rectifier potassium ion current, leading to increased risk of arrhythmia and SUDEP (Danielsson BR et al. Epilepsy Res 2005;63:17-25). The above findings might prompt a review of cardiac function by ECG especially in young female patients with idiopathic generalized epilepsy treated with LTG.

\title{
VALPROIC ACID-INDUCED HAIR CURLING
}

A 47-year-old white female patient treated with valproic acid (VPA) $500 \mathrm{mg} 3 \mathrm{xd}$, at Utrecht University, the Netherlands, developed curling of the hair which gradually resolved over 5 years continuous therapy, with blood levels ranging from 97 to $146 \mathrm{mg} / \mathrm{L}$. Thinning of the hair with spots of alopecia preceded the curling effect and persisted after curling resolved. She had dyed her hair long before the curling appeared, but she had never had a permanent wave hair styling. This report of a transient perming effect of VPA is considered unique. (Wilting I, van Laarhoven JHM, de Koning-Verest IF, Egberts ACG. Valproic acidinduced hair-texture changes in a white woman. Epilepsia Feb 2007;48:400-401). (Reprints: Ms I Wilting, Utrecht University, Faculty of Science, Utrecht Institute for Pharmaceutical Sciences, PO Box 80 082, 3508 TB Utrecht, The Netherlands).

COMMENT. VPA is known to cause alopecia, thinning of the hair, and hair color changes. Changes in hair texture are also reported, including curliness in $2 \%$ of 250 patients (Jeavons PM et al. Lancet 1977;1:359), but rarely transient.

\section{ATTENTION DEFICIT DISORDERS}

\section{LOW BIRTH WEIGHT AND ATTENTION DEFICIT DISORDER}

The relation of low birth weight to the risk of attention deficit hyperactivity disorder was determined in a population-based sample of 1,480 twin pairs ascertained from the Swedish twin registry in the period 1985-1986. Eighteen twin pairs at 8-9 years of age and 10 twin pairs at 13-14 years were discordant for both birth weight and ADHD criteria. The child with ADHD was smaller in 11 of 18 pairs at 8-9 years and in 9 of 10 pairs in adolescence $(\mathrm{P}=0.011)$. The lighter twin had on average $13 \%$ higher ADHD symptom score at age $8-9$ years $(\mathrm{P}=0.006)$ and $12 \%$ higher $\mathrm{ADHD}$ score at age $13-14$ years $(\mathrm{P}=0.018)$ compared with 
the heavier twin. Similar effect sizes were found in $\mathrm{MZ}$ and $\mathrm{DZ}$ twins, and the associations did not diminish when genetic influences were controlled. Fetal growth restriction has a modest but significant environmental influence on the development of ADHD. (Hultman $\mathrm{CM}$, Torrang A, Tuvblad C et al. Birth weight and attention-deficit/hyperactivity symptoms in childhood and early adolescence: a prospective Swedish twin study. J Am Acad Child Adolesc Psychiatry March 2007;46:370-377). (Respond: Dr Christina M Hultman, Department of Medical Epidemiology and Biostatistics, Karolinska Institute, Box 281, SE171 77, Stockholm, Sweden).

COMMENT. Low birth weight and fetal growth restriction are risk factors for the development of ADHD in childhood, and the association is independent of genetic and other environmental influences such as maternal smoking and exposure to drugs during pregnancy.

Effect of long-term treatment with stimulant medication on growth of ADHD children. The reports of retarded growth of ADHD children treated with stimulants have been questioned in two recent studies (Pliszka SR et al, 2006; Spencer TJ et al, 2006) showing minimal or no significant effects on growth. A letter to the editor (Poulton A. J Am Acad Child Adolesc Psychiatry March 2007;46:305-6) points out that studies on growth should include treatment naïve patients, because growth velocities progressively normalize with prolonged treatment. This criticism could be applied to the Pliszka study in which the majority of the cohort were previously treated, but not to that of Spencer in which absence of growth effects was not related to previous stimulant exposure. In an earlier uncontrolled study, an analysis of heights of 50 children failed to confirm a growth suppressant effect of methylphenidate, when conservative doses were employed and treatment was interrupted at weekends and on vacations (Millichap JG. Attention Deficit Hyperactivity and Learning Disorders. Chicago, PNB Publishers, 1998;175-6).

\section{HEADACHE DISORDERS}

\section{OUTCOMES OF CHRONIC DAILY HEADACHE IN ADOLESCENTS}

The outcomes and predictors of chronic daily headache $(\mathrm{CDH})$ were determined in a 2-year longitudinal study of a sample of 122 adolescents (32 male/90 female; ages 12-14) with annual telephone follow-up by neurologists at Taipei Veterans General Hospital, Taiwan. Response rates were $92 \%$ in 2001 and $84 \%$ in 2002. Average monthly headache frequency was $11.0+/-9.7$ days in 2001 and $7.7+/-6.5$ days in 2002. Persistence rates of $\mathrm{CDH}$ were $40 \%$ in 2001 and $25 \%$ in 2002. Medication overuse was $20 \%$ at baseline and $6 \%$ at 2 years. Based on the International Classification of Headache Disorders- $2^{\text {nd }}$ ed 2004 (ICHD-2), the prevalence of migraine was not significantly changed during follow-up (67\% at baseline and $60 \%$ at 2 years), whereas tension-type headache (CTTH) decreased from $86 \%$ to $46 \%$ in the same time interval $(\mathrm{P}<0.001)$. When using ICHD-2 appendix criteria (2006), chronic migraine prevalence increased 3 to 4 times when compared with the original ICDH-2 criteria. Chronic migraine became more common than CTTH in patients with persistent $\mathrm{CDH}$ in 2001 and 2002. Headaches adversely affected learning at school in 56\% in 2001 and $57 \%$ in 2002; 7 (6\%) dropped out of school during the 2-year follow-up. Poor outcome predictors included female gender, chronic migraine (by ICHD-2 appendix criteria), medication 